\title{
A Comparative Study on English Translations of Military Terms in Sun Tzu: The Art of War
}

\author{
Jianning Zheng \\ Beijing Normal University, Beijing, China
}

\begin{abstract}
Sun Tzu: The Art of War, which was written by Sun Wu in the end of the Spring and Autumn period, is the oldest and the most famous military treatise in the world, and it has achieved a great popularity outside China. Sun Tzu is a book with universal value and eternal wisdom, which can be applied by people of all the times to human activities of all the fields. This book incorporates many military terms which are important for the understanding of it. All the Chinese commentators in the history have their own understanding of these terms, and the same is true for Sun Tzu's English translators. The author of this paper aims to compare two English translations of Sun Tzu: the translation by American comparative philosopher Roger T. Ames and the translation by Chinese scholar Lin Wusun. The author selects twelve military terms from Sun Tzu and compares the translations of these two translators and makes an evaluation and comment on their renderings. In the end, he will try to explore the reasons behind the two translators' translation methods.
\end{abstract}

Index Terms-Sun Tzu: The Art of War, military terms, Roger T. Ames, Lin Wusun, English translations

\section{INTRODUCTION}

Sun Tzu: The Art of War, which has thirteen chapters, is the oldest and the most famous military treatise existed in the world. It is believed that it was written by Sun Wu, who was a contemporary of Confucius (551-479 B.C.), in the end of the Spring and Autumn period (770 - 453 B.C.), though some scholars have argued that it had come into being in the Warring States period (453-221 B.C.) and it was compiled by Sun Wu's disciples. There are little historical records on Sun $\mathrm{Wu}$, but we know that he was born in $\mathrm{Qi}$, which is present day Shandong province, and went south to serve the state of $\mathrm{Wu}$, which is present day Jiangsu and Zhejiang province. There are three edition systems of Sun Tzu: the first is Sun Tzu with Notes of Eleven Commentators (shi yi jia zhu sun zi), which was passed down from the South Song dynasty (1127-1279 A.D.). The second is The Seven Military Classics of Ancient China (wu jing qi shu), which was compiled in 1080 under the auspice of Emperor Shen of the North Song dynasty (960-1127). The third is the bamboo strips which were unearthed in 1972 in Silver Sparrow Mountain (yin que shan) of Linyi, Shandong province, and date back to the second century B.C. Sun Xingyan, a scholar from the Qing dynasty (1636-1912), also emended an edition: Sun Tzu with Notes of Ten Commentators (sun zi shi jia zhu), which belongs to the first edition system and is the base of many influential English translations.

Sun Tzu was ranked first in The Seven Military Classics and it was called The Source of Chinese Military Wisdom. In his forward to the translation of Samuel Griffith (1963), British military theorist Liddell Hart said: “Sun Tzu's essays on 'The Art of War' form the earliest of known treatises on the subject, but have never surpassed in comprehensiveness and depth of understanding......Among all the military thinkers of the past, only Clausewitz is comparable, and even he is more 'dated' than Sun Tzu, and in part antiquated, although he was writing more than two thousand years later" (p. v). Sun $T z u$ is a book with universal value and eternal wisdom, which can be applied by people of all the times to human activities of all the fields.

The English translation of Sun Tzu began in 1905 by British captain E.F. Calthrop, who was serving in Japan and studying the Japanese language. His translation was named Sonshi: The Chinese Military Classic, and in 1908, he published a new translation: The Book of War: The Military Classic of the Far East. According to Luo Tian and Zhang Meifang (2015), over 50 translation versions of Sun Tzu have been published in the English translation history of it (p. 51), and the translators are from different countries and with different cultural as well as professional background. They read and interpreted Sun Tzu from their own specific perspectives. To know whether their background had affected their renderings of Sun Tzu, how the influence was manifested, and how Sun Tzu's meanings were reflected in different translations, it is necessary to make a comparative study of the different translations by different translators.

This paper focuses on two translations of Sun Tzu: the translation by Professor Roger T. Ames (1947-) and the translation by Lin Wusun (1928-). Professor Roger T. Ames is an American comparative philosopher, internationally renowned scholar of Confucian studies. He obtained his doctor's degree in London University in 1978, and had been a professor of philosophy in Hawaii University from 1978 to 2016. Lin Wusun is a famous Chinese scholar and translator. He had been the director of China International Publishing Group (1988-1993) and vice director of Translators

\footnotetext{
* This work was supported by the project of National Funding for Humanities and Social Sciences: The Construction and Application of the Cloud Platform of English Translations of Chinese Classics [grant number 17AYY012].
} 
Association of China (1992-2004). Ames's translation was published in 1993 by Ballantine Books, New York, which was named Sun-Tzu: The Art of Warfare: The First English Translation Incorporating the Recently Discovered Yin-Chueh-Shan Texts, and it was based on Wu Jiulong's Emendations and Commentaries of Sun Tzu (sun zi jiao shi). Lin's translation: Sun Zi: The Art of War, was published in 1994 in People's China Press, and republished in 1999 in Foreign Languages Press, and then republished in 2003 in Long River Press of San Francisco. His translation was based on the text emended by Wu Rusong and Wu Xianlin.

\section{Military Terms In SUN TZU: The ART OF WAR}

Sun Tzu is first and foremost a military classic, which, according to China's traditional methods of classifying books, belongs to Military books (bing shu). During the reign of Emperor Cheng of the Western Han dynasty (202 B.C.- 8 A.D.), Liu Xiang (79 B.C. - 8 B.C.) was ordered to make a list of the existing books, and his list was named Special Records (bie lu). After the death of Liu Xiang, his son, Liu Xin (?-23 A.D.) continued the compiling effort and finished a work called Seven Categories (qi lue). These two books have the first official method of classifying books in the history of China, in which Military books is regarded as one of the six main categories. Sun Tzu was put in both the two works into the category of Military books (Liu Xiang \& Liu Xin, 2008 p74, p166). This classifying method was adopted by Ban Gu of the Eastern Han dynasty (25 A.D.-220 A.D.) in his On the Arts and Literature of The History of Former Han Dynasty, in which he divided Military books into four categories: On Strategies; On Xing and Shi; On Yin and Yang and On Military Techniques (the meanings of those terms will be discussed later) (Ban Gu, 1997 p1756-1762). Sun Tzu, according to Li Ling, encompasses all those four categories, as the first three chapters belong to Strategies, chapter four to chapter six belong to Xing and Shi, chapter seven to chapter eleven belong to Military Techniques (Li Ling, 2010 p1-2), and Sun Tzu also has elements of Yin and Yang (Li Ling, 1990 p201-204).

Sun Tzu was written in the end of the Spring and Autumn period, therefore, its content had inevitably been influenced by the social culture and productive power of that times. The military management styles and weapons are also characteristic of that period. Also, as Mao Yuanyi, a scholar of the Ming dynasty (1368-1644 A.D.) commented: "Sun Wu had not neglected those military masters before him, and military scholars after him should not neglect him", Sun Wu had also been influenced by military masters of his home state of Qi, such as Jiang Ziya, Guan Zhong, Sima Rangju and so on. The military thought in Sun Tzu is also the product of Sun Wu's rich military experience and deep reflections on war. With the assistance of Sun Wu, the king of Wu had achieved several victories, such as the battle in Boju (506 B.C.), in which he defeated the state of Chu; the battle in Ailing (484 B.C.), in which he defeated Qi; and the meeting in Huangchi (482 B.C.), in which he thwarted the state of Jin. To truly understand Sun Tzu, including its historical implications, its origin and Sun Wu's thought, and retell them to readers of other languages, the translator has to figure out the meanings of military terms in Sun $T z u$, as they are the essence of this treatise and the carrier of its military thought.

Military terms belong to specialized language, and they are used specifically in the military setting to illustrate military affairs. Some of them have also been borrowed by people of other fields to be used metaphorically. Military terms can be divided into different categories according to different classifying methods. The first official compilation of Chinese military terms began in 1906 by the Army of the Northern Warlords (bei yang lu jun), in which there are ten categories: military affairs, army forms, terrains, army marching, army stationing, encampment, logistics, engineering, military exercise and weapons (Su Guiliang, 1990 p184). Zhu Liangcai (1998), a scholar on Sun Tzu and military history, classified military terms into five categories: military weapons, military regulations, military strategies, military techniques and military formations. (p. 111) According to Dictionary of Sun Tzu, which was edited by Wu Rusong and published in 1993, there are 99 military terms in Sun Tzu (p. 14-26). But in the second edition of this dictionary, which was published in 1995, the military terms are condensed into 79 (p. 14-27). In A Dictionary of Sun Tzu's Art of War, which was published in 2015 and is the revised and enlarged edition of the last two dictionaries, there are 254 military terms, and they are grouped into eight categories: military strategies, military tactics, general qualities, opposite categories, military operations, organization and weapons, battlefield environment, and information and intelligence. (p. 353) This study adopts this listing and classifying of Sun Tzu's military terms and chooses typical terms from each category to make a comparative study of Ames's and Lin's translations.

\section{A Comparative Study on English Translations of Military Terms in Sun Tzu: The ART of WaR}

In this section, we will focus on twelve military terms in Sun Tzu, which have been chosen from the eight categories classified in A Dictionary of Sun Tzu's Art of War. We will discuss the meanings of each terms, examine how the two translators have translated them, and make a comment and evaluation on their translations.

\section{A. Military Strategies}

Example 1: “十六字诀”

This term refers to“上兵伐谋，其次伐交，其次伐兵，其下攻城”, which is from chapter three of Sun Tzu.

Ames's translation: The best military policy is to attack strategies; the next to attack alliances; the next to attack soldiers; and the worst to assault walled cities. 
Lin's translation: The best policy in war is to thwart the enemy's strategy. The second best is to disrupt his alliances through diplomatic means. The third best is to attack his army in the field. The worst policy of all is to attack walled cities.

Lin's translation is much longer than the Ames's, as Lin tries to expose the implied meanings of the original and Ames tries to preserve the concise style of it. Lin's translation has four sentences with four full stops, while Ames's translation has just one sentence, which is divided into four parts by semicolons, and the second, the third and the last part do not have the predicate "is". Lin adds "through diplomatic means" and "in the field" to make the original meaning clearer, but Ames's translation do not make this distinction. "The best policy in war" is more accurate than “the best military policy" to translate “上兵”, because Sun Tzu is talking here the matters of war and confrontation, and "military policy" has a much wider range of meanings. Ames uses one word "attack" to translate the verb “伐”, which is used before “谋”“交” and “兵”, but Lin translates them into three verbs "thwart" "disrupt” and "attack", which is more appropriate in expressing the original meaning. According to Huang Pumin (2010), “伐交” means to flex your muscle to deter your enemy and do not resort to conflict and war. “交” means the two sides of your troops are facing each other on the battlefield (p. 108-113). However, both the two translators translate “伐交” into "attack/disrupt alliances”, but attack alliances is also a kind of “伐谋”.

Example 2: 形

“形” occurs 32 times in Sun Tzu, and its usages in chapter four, five and six refer to military strategies. We take one example from each of the three chapters:

（1）“称胜者之战民也, 若决积水于千仞之谿者, 形也。”

(2) “形之, 敌必从之;”

(3) “故形兵之极, 至于无形; ”

Ames's translation:

(1) It is a matter of strategic positioning (hsing) that the army that has this weight of victory on its side, in launching its men into battle, can be likened to the cascading of pent-up waters thundering through a steep gorge.

(2) .......shows himself (hsing), and the enemy is certain to follow.

(3) The ultimate skill in taking up a strategic position (hsing) is to have no form (hsing).

Lin's translation:

(1) So great is the disparity of strength that a victorious army goes into battle with the force of an onrushing torrent which, when suddenly released, plunges into a chasm a thousand fathoms deep. This is what we mean by disposition.

(2) ......puzzle him with deceptive appearances according to which he will react.

(3) Now the ultimate in troop disposition is to leave no trace of how they are disposed.

There are four "形” in these three sentences. Ames translates them into "strategic positioning" "shows himself" "a strategic position" and "form" respectively, and adds the pronunciation of “形” after each translation to show that they are the same Chinese character. Lin translates the four "形” into "disposition" "puzzle him with deceptive appearances" "troop disposition" and "how they are disposed". The first “形" in this example means the appearance or the arrangement your army takes, and it cannot be recognized by your enemy. It's like you are in a position thousand rens' high, and nobody can see you. But when you begin to strike your enemy, it's like the water rushing from this high place and its force cannot be resisted. The second “形” means to show fake appearances or false arrangements of your army so that your enemy will be cheated and make wrong decisions. The third and the fourth “形” are related to each other, as the whole sentence means that to make your army have an appearance or take an arrangement, the best thing you can do is to make them unrecognizable to your enemy. Therefore, Lin's translation of the four “形” is more accurate and appropriate in reflecting the original meanings.

\section{B. Military Tactics}

Example 3: 兵无成势

This term is from chapter six, in which the whole sentence is: “故兵无成势, 无恒形。能因敌变化而取胜者, 谓之 神。”

Ames's translation: Thus an army does not have fixed strategic advantages (shih)......

Lin's translation: There is no fixed pattern in the use of tactics in war......

This term has the word “势”, which Ames explains in detail in the introduction of his translation. Ames translates “兵” in this term into “army”, while Lin translates it into “war”. Ames translates “无成势” (or “无常势” in the text Lin based his translation) into "does not have fixed strategic advantages (shih)", while Lin translates it into "there is no fixed pattern in the use of tactics". In the original text, Sun Wu likens an army to the water. As water makes its flow, it has different strength or style according to different ground conditions it encounters. The same is true to an army, and it will have different strategic situations according to different conditions of his enemy. Therefore, it should make itself flexible and adjust its way of striking to suit different situations. According to Mei Yaochen, “势” means engaging your enemy in this context, therefore, “兵无成（常）势” means that an army has different kinds of engagement and does not 
have the same kind of strategic situation all the time. The author cannot fully agree with both the two translators' translations.

\section{General Qualities}

\section{Example 4: 静以幽, 正以治}

This term is from chapter eleven, in which the whole sentence is: “将军之事，静以幽，正以治。”

Ames's translation: As for the urgent business of the commander: He is calm and remote, correct and disciplined.

Lin's translation: It is the responsibility of the commander to be calm and inscrutable, to be impartial and strict in enforcing discipline.

In this term, “以” means “and”, and “静” “幽” “正” “治” are four adjectives to describe qualities a general should have. Both Ames and Lin translate “静” into "calm”. Ames translates “幽” into "remote”, while Lin translates it into “inscrutable". Ames translates “正” into "correct", while Lin translates it into "impartial”. Ames translates “治” into “disciplined”, and Lin translates it into "strict in enforcing discipline”. As for “幽” and “正”, Lin's choice of words are more appropriate, because “幽” means that a general should keep his plan in secret and do not let his men know what's in his mind, and “正” means that he should be fair in managing his army. As for “治”, Mei Yaochen also interprets it as "self-disciplined", but considering the context, this word means that a general should be able to enforce discipline in his army. Therefore, Lin's translation of this term is more appropriate.

\section{Opposite Categories}

Example 5: 奇正

“奇” and “正” are opposite to each other, the former occurs seven times in Sun Tzu, and the latter occurs nine times. We take the three sentences that have both the two words, and examine the two translators' translations.

(1) 三军之众, 可使毕受敌而无败者, 奇正是也。

（2）凡战者, 以正合, 以奇胜。

（3）战势不过奇正，奇正之变，不可胜穷也。

Ames's translation:

(1) It is "surprise" (ch'i) and "straightforward" (cheng) operations that enable one's army to withstand the full assault of the enemy force and remain undefeated.

(2) Generally in battle use the "straightforward" to engage the enemy and the "surprise" to win the victory.

(3) For gaining strategic advantage (shih) in battle, there are no more than "surprise" and "straightforward" operations, yet in combination, they produce inexhaustible possibilities.

Lin's translation:

(1) Thanks to the combined use of qi (奇) and zheng (正) tactics, the army is able to withstand the onslaught of the enemy forces.

(2) Generally, in battle, use zheng to engage the enemy and use qi to score victory.

(3) In military tactics, there are only two types of operation, qi and zheng, yet their variations are limitless.

Both the two translators are consistent in their translation of “奇” and “正” in the above three sentences, and the translations in the first sentence have some added information. In their notes to the translation, both the two translators have the same reasonable explanation to “奇” and “正”, but their translations are different. Ames translates these two words into "surprise" (ch'i) and "straightforward" (cheng), while Lin translates them into qi (奇) and zheng (正). Ames offers the literal meanings and the pronunciations of the two words, while Lin gives the pronunciations and the Chinese characters in his translation. Lin's translation is more foreignized while Ames's translation is more domesticated.

Example 6: 虚实

“虚” and “实” are two opposite words, both of which occur six times in Sun Tzu. We take the two sentences that have both the two words, and examine the two translators' translations.

（1）兵之所加, 如以砽投卵者, 虚实是也。

（2）兵之胜, 避实而击虚。

Ames's translation:

(1) It is the distinction between "weak points" and "strong points" that makes one's army falling upon the enemy a whetstone being hurled at eggs.

(2) ......so on the path to victory avoid the enemy's strong points and strike where he is weak.

Lin's translation:

(1) By staying clear of the enemy's strong points and striking at his weak points, it is able to fall upon the enemy like using a whetstone to crush an egg.

(2) To operate the army successfully, we must avoid the enemy's strong points and seek out his weak points. 
Both the two translators translate “虚” and “实” into "weak points” and "strong points", but in their expressions of these two sentences, there are differences. As for “虚实是也”, Lin's translation can better expose the implied meanings of the original than the Ames's. And in translating “击虚”, Ames is more flexible in the choice of words while Lin is more rigid. Ames's rendering "strike where he is weak" is more appropriate than Lin's "seek out his weak points".

Example 7: 阴阳

“阴” and “阳” are also opposite to each other, the former occurs three times in Sun Tzu, and the latter occurs five times. We take the two sentences that have both the two words, and examine the two translators' translations.

(1) 天者, 阴阳、寒暑、时制也。

(2) 凡军好高而恶下, 贵阳而贱阴。

Ames's translation:

(1) Climate is light and shadow, heat and cold, and the rotation of the seasons.

(2) Generally speaking, an army prefers high ground and dislikes the low, prizes the sunny side and shuns the shady side......

Lin's translation:

(1) By "heaven", I mean the effects of night and day, of good and bad weather, of winter's cold and summer's heat; in short, the conduct of military operations in accordance with the changes of natural forces.

(2) Generally speaking, a maneuvering army prefers high, dry ground to low, wet ground; it prizes the sunny side and shuns the shady side......

Both the two translators translate “阴” and “阳” in the second sentence into "shady side" and "sunny side", but their translations of them in the first sentence are different. Ames translates “阴阳” in the first sentence into "light and shadow", while Lin uses more words to translate it: "I mean the effects of night and day, of good and bad weather". The original meanings of “阴” and “阳” are the shady side and the sunny side of a mountain, but these two words have more sophisticated meanings in Chinese philosophy. They concern with Chinese people's views of cosmology, and that all the things in the universe have these two opposite categories. Sun Wu puts “阴” and “阳” in the category of “天”, and “天” concerns with the right timing here, such as the right time in a day, the right climate conditions, the right seasons and so on. Therefore, “阴” and “阳” are also about the right timing. In the translation of “天”, it should not be restricted to “climate”, and Lin's translation of "heaven" has too much religious implications. “阴阳” also contains a wide range of meanings, Ames's translation of "light and shadow" is not so much about the right timing, and Lin's translation of “night and day" and "good and bad weather" are only part of the meanings of “阴阳”. Therefore, the author proposes the transliteration of “天” “阴” and “阳”, and add notes to explain the meanings of these words.

\section{E. Military Operations}

Example 8: 火队

This term is from chapter twelve, in which the whole sentence is “凡火攻有五, 一曰火人，二曰火积，三曰火辎， 四曰火库, 五曰火队。”

Ames's translation: There are five kinds of incendiary attack: The first is called setting fire to personnel; the second, to stores; the third, to transport vehicles and equipment; the fourth, to munitions; the fifth, to supply installations.

Lin's translation: There are five targets for an attack with fire: 1) men and horses, 2) grain and fodder, 3) wagons and equipment, 4) warehouses, and 5) supply routes.

Chinese commentators in the history have different understandings of this term. According to Li Quan, Du Mu, Zhang Yu and Mei Yaochen, “队” means “team” or “band of army”, but that's also a kind of “人” in “火人”. Jia Lin and He Yanxi propose that “队” is the same as “㯌”, which means the route of an army's food supply. Considering the meanings of “火人” “火积” “火辎” and “火库”, this explanation of “火队” is more reasonable. Ames translates this term into "setting fire to supply installations", and Lin translates it into "supply routes". "Installation" usually refers to permanent posts or stations, which is the meaning of “库”, and cannot convey the meaning of “队”, and Lin's translation of "supply routes" is more appropriate.

\section{F. Organization and Weapons}

Example 9: 选锋

This term is from chapter ten, in which the whole sentence is “将不能料敌, 以少合众, 以弱击强, 兵无选锋, 北。”,

Ames's translation: If the commander, unable to assess his enemy, sends a small force to engage a large one, send his weak troops to attack the enemy's best, and operates without a vanguard of crack troops, the result will be rout.

Lin's translation: If the commander, unable to assess his enemy, sends a small force to engage a large one, pits his weak forces against the enemy's strong, and operates without a vanguard of crack troops, the result will be rout. 
“选锋” means the elite and the strongest soldiers that have been chosen from your army. This method of organizing an army can enhance the overall strength of it. Both the two translators translate this term into "a vanguard of crack troops", which can convey the original meaning properly. The two translators' rendering of the whole sentence is the same except the translation of “以弱击强”. Ames uses “troops" which is different from "force” used before, and Lin uses the word "force" twice. Ames translates “强” into "best”, while Lin translates it into "strong”. Ames's choice of words is more flexible while Lin is relatively rigid. Lin is more inclined to stick to the original word meanings.

Example 10: 轒輼

This term is from chapter three, in which the whole sentence is “修橹轒輼, 具器械, 三月而后成”.

Ames's translation: To construct siege screens and armored personnel vehicles and to assemble all of the military equipment and weaponry necessary will take three months......

Lin's translation: For it takes at least three months to get the mantlets and shielded vehicles ready and prepare the necessary arms and equipment.....

“轒輼” is a kind of vehicle used in assaulting walled cities in ancient times. It has four wheels and has hard objects over its body so that it can resist the enemy's arrows, wood blocks and stones. One “轒輼” has the room for more than ten soldiers, and it can protect them to get near to the enemy's city wall. But according to Du Mu, the purpose of this vehicle is to transport earth to fill up the enemy's moat. Ames translates this term into "armored personnel vehicles", which restricts the purpose of this vehicle to the transportation of soldiers. Lin translates it into "shielded vehicles" and does not specify the functions of it. The author proposes the transliteration of this term and add note to explain the structure and possible purposes of this vehicle.

\section{G. Battlefield Environment}

Example 11: 九地

“地” is the most frequently used word in Sun Tzu, in which it occurs 88 times. “九地” is from chapter eleven, which refers to “散地、轻地、争地、交地、瞿地、重地、圮地、围地、死地”.

Ames's translation: ......the kinds of terrain include scattering terrain, marginal terrain, contested terrain, intermediate terrain, the strategically vital intersection, critical terrain, difficult terrain, terrain vulnerable to ambush, and terrain from which there is no way out.

Lin's translation: ......there are nine kinds of regions to consider: dispersive (san 散), marginal (qing 轻), contested (zheng 争), open (jiao 交), focal (qu 衖), critical (zhong 重), difficult (pi 圮), beleaguered (wei 围) and deadly (si 死).

These nine kinds of “地” is the “势” aspect of it, compared with the “形” aspect of it, such as “通” “挂” “支” “险” “险” and “远”. The main difference between the two translators' translations is that Ames only translates the meanings of the nine terms, while Lin also adds the pronunciation and the Chinese character after each translation. Ames translates “地” into “terrain”, which he also uses to translate the “地” in “地形” of chapter ten. He doesn't make a distinction between the “形” and “势” aspects of “地”. Lin translates “地” in this term into “regions” and “地” in “地 形” of chapter ten into “terrain”, which has made a distinction between the two. To translate “散” “轻” “重” and “圮” into "scattering/ dispersive" "marginal" "critical" and "difficult" cannot accurately express the original meanings, and transliteration plus notes should be a better option. “交地” means the place where all parties can come and go freely, so “open” is a better translation than “intermediate”. “忂地” means the place where there are other countries besides you and your enemy, therefore, it is to your advantage to go there first and get the help of those other countries. Ames's translation "the strategically vital intersection" is a better rendering than Lin's translation of "focal".

\section{H. Information and Intelligence}

Example 12: 先知

“知” is also a frequently used word in Sun Tzu, in which it occurs 79 times. “先知” is a term that occurs two times in chapter thirteen. We take these two sentences and compare the two translators' translations.

“故明君贤将, 所以动而胜人, 成功出于众者, 先知也。”

“先知者, 不可取于鬼神......”

Ames's translation:

(1) Thus the reason the farsighted ruler and his superior commander conquer the enemy at every move, and achieve successes far beyond the reach of the common crowd, is foreknowledge.

(2) Such foreknowledge cannot be had from ghosts and spirits.....

Lin's translation:

(1) The enlightened sovereign and the capable commander conquer the enemy at every move and achieve successes far surpassing those of ordinary people because they possess "foreknowledge".

(2) This "foreknowledge" cannot be obtained from ghosts or spirits, nor from gods.....

“先知” refers to the use of spies to get the intelligence of your enemy before the war begins. Ames translates this term into foreknowledge without quotation marks, and Lin translates it into "foreknowledge" with quotation marks, which highlights it and makes it a military term. "Foreknowledge" means the knowledge of something before it exists 
or happens, and it has a much richer meanings than what Sun Wu intended by “先知”. "Foreknowledge” can also mean your precise anticipation of something's coming. Therefore, this word is not the best choice to translate “先知”. It is advisable to explain this term's meaning in the translation, and translate it into "the intelligence of your enemy before the war begins".

\section{CONCLUSION}

As the oldest and the most famous military treatise existed in the world, Sun Tzu: The Art of War has achieved a great popularity and attracted a large audience outside China. It is a success story of cross-cultural communications, yet insufficient research has been done on its English translators, who are from different countries and with different cultural as well as professional background. This study focuses on the English translations of Sun Tzu by American comparative philosopher Roger T. Ames and Chinese scholar Lin Wusun, and examines their translations of twelve military terms in Sun Tzu. The study shows that both the two translators did a good translation, but there are terms which the author cannot agree with their translations, such as “伐交” and “无成势”. As far as the twelve military terms are concerned, Lin's translation is in general more accurate, but in the translation of some terms, Ames's rendering is better than Lin's. Lin is inclined to use more words to expose the implied meanings of the original, while Ames's translation is more concise and can better preserve the style of the original. Lin's translation is more foreignized and sticks to the original words' meanings, while Ames's choice of words is more diversified and his translation is more domesticated. In the translation of some terms, such as “天” “阴” “阳” “轒輼”, which contain rich meanings, the author proposes transliteration plus notes, so that translators can take readers to the original culture and show the rich meanings of it.

Lin Wusun is a Chinese scholar who is 19 years older than Roger T. Ames, so he has the advantage of understanding the original text. Also Lin considers Sun Tzu and The Analects as the two most important classics in traditional Chinese culture, as the former concerns with Wu (武) and the latter concerns with Wen (文) aspect of managing the country. Lin's translation is included in the Library of Chinese Classics, and his aim is to promote Sun Tzu to the outside world, so he preserves much Chinese elements in his translation and sticks to the original words' meanings. Ames, as a native English speaker, is flexible in his English language usages. His translation was initiated by the Random House (Xiaoli Tan et al, 2015 p140), so he may lack Lin's inclination to explore the implied meanings of the original Chinese words, and his translation preserves the concise style of the original. Ames's book of translation contains a great amount of information and its format shows a high standard of scholarship. In his long introduction, he explains the philosophical presuppositions of Sun Tzu, and asks foreign readers to apply Sun Wu's worldview in their reading of the text. That's the typical way of his translation of Chinese classics, which emphasizes the interpretive context of the original work.

\section{REFERENCES}

[1] Ames, R. T. (1993). Sun-tzu: The Art of Warfare. New York: Ballantine Books.

[2] Ban Gu. (1997). The History of Former Han Dynasty. Beijing: Zhonghua Book Company.

[3] Griffith, S. B. (1963). Sun Tzu: The Art of War. Oxford: Oxford University Press.

[4] Huang Pumin. (2010). Studies on Military Culture of the Pre-Qin and the Han Dynasties. Beijing: China Renmin University Press.

[5] Li Ling. (1990). New Explorations of Sun Tzu: Chinese and Foreign Scholars on Sun Tzu. Beijing: Chinese People's Liberation Army Press.

[6] Li Ling. (2010). The Only Rule: Sun Tzu’s Combat Philosophy. Beijing: SDX Joint Publishing Company.

[7] Lin, W. S. (1999). Sun Zi: The Art of War \& Sun Bin: The Art of War. Beijing: Foreign Languages Press.

[8] Liu Xiang \& Liu Xin. (2008). Lost Texts of Bie Lu and Qi Lue. Shanghai: Shanghai Classics Publishing House.

[9] Luo Tian \& Zhang Meifang. (2015). Fifties Years of Sun Tzu Translation Studies: Review and Forecast. Translation Quarterly $75,50-65$.

[10] Su Guiliang et al. (1990). Index of Military Literature. Beijing: Military Science Press.

[11] Wu Rusong. (1993). Dictionary of Sun Tzu. Shenyang: White Mountain Press.

[12] Wu Rusong. (1995). Dictionary of Sun Tzu. Shenyang: White Mountain Press.

[13] Wu Rusong \& Su Guiliang. (2015). A Dictionary of Sun Tzu's Art of War. Shenyang: White Mountain Press.

[14] Xiaoli Tan \& Tianyuan Huang. (2015). Translating Chinese philosophy on its own terms: an interview with Professor Roger T. Ames. Asia Pacific Translation and Intercultural Studies 2.2, 139-149.

[15] Zhu Liangcai. (1998). An Introduction to The Study of Chinese Ancient Military Language. Hangzhou: Zhejiang Education Press. 
Jianning Zheng was born in Shandong, China in 1986. He is a PhD student on Translation Studies in Beijing Normal University in Beijing, China. His research interests include English translation of Chinese classics, corpus translation studies, and English translation of Sun Tzu: The Art of War. 